\title{
COMUNICAÇÃO INFORMAL E O SUCESSO DE PROJETOS DE DESENVOLVIMENTO SOFTWARE: UM ESTUDO DE CASO NO SETOR BANCÁRIO BRASILEIRO
}

\author{
INFORMAL COMMUNICATION FEATURES AND SOFTWARE PROJECTS \\ SUCCESS: A BRAZILIAN BANKING SECTOR CASE STUDY
}

\author{
Leandro Zocaratto Rezende \\ Mestre em Ciências pela EACH-USP \\ Universidade de São Paulo - SP \\ São Paulo, SP - Brasil \\ leandro.zocaratto@gmail.com \\ Edmir Parada Vasques Prado \\ Doutor em Administração pela FEA-USP \\ Universidade de São Paulo - SP \\ São Paulo, SP - Brasil \\ eprado@usp.br \\ Alexandre Grotta \\ Mestre em Ciências pela EACH-USP \\ Universidade de São Paulo - SP \\ São Paulo, SP - Brasil \\ grotta@usp.br
}

\section{Resumo}

O gerenciamento de projetos de tecnologia é desafiador. Apesar da comunicação ser um dos fatores mais importantes para o sucesso de um projeto, há poucos trabalhos na literatura que relacionam a comunicação informal (CI) com sucesso em projetos. Esta pesquisa tem como objetivo analisar a influência da CI no sucesso de curto e médio prazo de projetos de desenvolvimento de software em uma instituição bancária brasileira. Para atingir esse objetivo, fez-se uma revisão bibliográfica sobre o tema de comunicação e sucesso em projetos. A pesquisa possui uma abordagem qualitativa e utilizou estratégia de estudo de caso. Foram entrevistados doze profissionais de desenvolvimento de software no primeiro semestre de 2019. A pesquisa constatou uma associação entre CI com eficiência do projeto e contribuição para a equipe do projeto. Não foi constatada associação entre $\mathrm{CI}$ e contribuição para o cliente. Além disso, a CI apresentou mais contribuições nos projetos com abordagem cascata do que em projetos ágeis.

Palavras-chave: Gestão da comunicação. Sucesso em projetos. Desenvolvimento de software.

\begin{abstract}
Technology project management is challenging. Although communication is one of the most important factors for project success, there are few studies in the literature that relate informal communication (IC) with success in projects. This research aims to analyze the influence of IC on the short and medium term success of software development projects in a Brazilian banking institution. To achieve this goal, we made a bibliographic review on the theme of communication and project success. The research has a qualitative approach and used a case study strategy. Twelve software development professionals were interviewed in the first half of 2019. The survey found an association between CI with project efficiency and contribution to the project team. No association was found between CI and contribution to the client. In addition, CI made more contributions in projects with waterfall approach than in agile projects.
\end{abstract}

Keywords: Communication management. Project success. Software development.

\section{Cite como}

American Psychological Association (APA)

Rezende, L. Z., Prado, E. P. V., \& Grotta, A. (2021, set./dez.). Comunicação informal e o sucesso de projetos de desenvolvimento software: um estudo de caso no setor bancário brasileiro. Revista de Gestão e Projetos (GeP), 12(3), 143-171. https://doi.org/10.5585/gep.v12i3.19393 


\section{Introdução}

A maioria dos pesquisadores, especialistas, profissionais e acadêmicos acredita que os projetos de tecnologia da informação (TI) falham regularmente (Qi et al., 2021; Li, Liu \& Ning, 2021). Isto também é um fato em projetos de desenvolvimento de software. Lu, Liu e Liu (2009) relatam que as altas taxas de insucesso em projetos de tecnologia de desenvolvimento de software vem se tornado um problema generalizado. Muitos trabalhos acadêmicos têm atribuído estes insucessos a problemas de comunicação. Srivastava e Kumar (2021) corroboram esta alegação e destacam a agilidade como um remédio universal para a falha usual no desenvolvimento de projetos de software.

Por outro lado, mesmo quando as medidas de sucesso são conhecidas, o gerenciamento de projetos de tecnologia ainda é desafiador (Al-ahmad et al., 2009). Além disso, a literatura sobre sucesso em projetos não convergiu para uma abordagem padrão que possa medir e avaliar o sucesso de um projeto (Shenhar \& Dvir, 2007). Segundo Buchanan (2008), muito do que se conhece sobre as falhas em projetos faz parte de estudos tardios que pouco contribuem para o entendimento delas. Ou seja, grande parcela dos projetos que encerram com estado considerado de falha, não são analisados ou estudados posteriormente para identificação de suas causas. Buchanan (2008) ainda alega que os projetos falham e que isto não irá mudar, a menos que as empresas comecem a avaliar em quais pontos eles falham e quais os motivos destas falhas.

A literatura sobre projetos de software mostra que a maior parte dos fatores de insucesso de um projeto de TI são de natureza comportamental, organizacional ou gerencial, e principalmente de comunicação (Hartman \& Ashrafi, 2002). Além disso, poucos trabalhos na literatura relacionam a comunicação com o sucesso em projetos. Nas bases de dados IEEE Xplore e ACM, nos últimos anos (2010 a 2020), apenas 11 trabalhos relacionam comunicação com sucesso em projetos. Mesmo assim, esses 11 trabalhos têm pouca relação com o contexto desta pesquisa e nenhum deles retrata a realidade brasileira. Dentro deste contexto, esta pesquisa pretende responder a seguinte pergunta de pesquisa: como a comunicação informal (CI) influencia o sucesso de projetos de desenvolvimento de software?

Como consequência, entender como a CI influencia o sucesso de projetos permite aos gestores de projeto obter uma maior taxa de sucesso em projetos de 
desenvolvimento de software. Com base neste contexto, e para responder à pergunta de pesquisa, definiu-se o seguinte objetivo geral: analisar a influência da CI no sucesso de curto e médio prazo de projetos de desenvolvimento de software em uma instituição bancária brasileira. Para atender a esse objetivo, foram definidos três objetivos específicos: (1) identificar, a partir da literatura, as principais dimensões de sucesso em projetos; (2) identificar, a partir da literatura, as características da comunicação relacionadas à formalidade; e (3) analisar a relação entre as características informais da comunicação em projetos de desenvolvimento de software e o sucesso obtido pelos projetos no curto e médio prazo.

$$
\text { Este artigo apresenta, }
$$
primeiramente, uma revisão da literatura sobre as dimensões de sucesso em projetos e as características da comunicação. Ao final da revisão da literatura é apresentado o modelo de referência da pesquisa. Em seguida são descritos os procedimentos metodológicos adotados, formando a base para a apresentação e discussão dos resultados. Por último, são apresentados os resultados e as conclusões da pesquisa.

\section{Fundamentação teórica}

Nesta seção são descritas as dimensões de sucesso em projetos e a comunicação no ambiente organizacional e de projetos. Cabe destacar, inicialmente, o conceito de sucesso em projetos. Em contraposição ao sucesso de gerenciamento de projeto, o sucesso de projetos refere-se aos objetivos e benefícios previstos pelo projeto para a organização como um todo. Embora seja de se esperar que o sucesso no gerenciamento do projeto leve ao sucesso do próprio projeto para a empresa, nem sempre isso ocorre (Shenhar \& Dvir, 2007; Morioka \& Carvalho, 2014).

\subsection{Dimensões de sucesso em projetos}

Machado e Martens (2015) apontam a importância em observar e mensurar fatores e causas de sucesso e de falha em projetos. Segundo esses autores, é possível encontrar e usar muitas abordagens diferentes sobre o sucesso do gerenciamento de projetos. Uma abordagem clássica e amplamente utilizada associa o sucesso em projetos às dimensões de custo, prazo e escopo, também conhecidas por "restrição tripla em projetos" (Dvir, Raz \& Shenhar, 2003). Por outro lado, Shenhar e Dvir (2007) defendem que estas três dimensões levam em consideração apenas os objetivos do 
planejamento, mas não as necessidades dos usuários, ou mesmo do negócio. Os autores definiram cinco dimensões que proporcionam uma estrutura adaptável às necessidades organizacionais e comerciais para avaliar o sucesso do projeto na maioria dos casos e em ambientes em geral. Em função disso, adotou-se nesta pesquisa este modelo multidimensional contendo cinco dimensões para avaliar o sucesso de projetos:

Eficiência do projeto. Cumprir as metas de tempo e orçamento. Representa uma medida de curto prazo: se o projeto foi completado ou não de acordo com o plano, considerando principalmente o cronograma e o orçamento.

Impacto no cliente. Cumprir os requisitos e alcançar satisfação do cliente, os benefícios e a lealdade. É a dimensão que representa os principais stakeholders, cujas percepções são críticas para a avaliação do sucesso do projeto. Essa dimensão mostra claramente como o resultado do projeto melhorou a vida ou o negócio do cliente e como ele abordou as necessidades dos clientes.

Impacto na equipe. Refere-se à satisfação, retenção e crescimento pessoal. Esta dimensão reflete como o projeto afeta a equipe e seus membros. Bons líderes de projetos estimulam e inspiram os membros de sua equipe e fazem com que o projeto seja uma experiência memorável e emocionante.

\section{Resultados comerciais. Refere-se a} retorno do investimento, participação de mercado e crescimento. Ela reflete o impacto imediato que o projeto tem na organização. Ou seja, níveis de vendas, rendas e lucros, assim como os fluxos de caixa e outras medidas financeiras.

Preparação para o futuro. Referese as novas tecnologias, novos mercados e novas capacidades. Trata-se dos benefícios de longo alcance do projeto. Ela reflete quão bem o projeto ajuda a organização a se preparar para o futuro.

O sucesso do projeto é um conceito dinâmico com implicações de curto e longo prazo, conforme mostra a Figura 1. A dimensão referente à eficiência pode ser avaliada no curto prazo, durante a execução e no momento da conclusão do projeto. A segunda e terceira dimensões normalmente se tornam claras alguns meses depois da conclusão do projeto, depois que o produto é entregue ao cliente e o impacto na equipe é mais aparente no contexto organizacional. A quarta dimensão, sucesso comercial, pode ser avaliada apenas após se ter conseguido um nível substancial de vendas e quando há um ponto de equilíbrio nos retornos do projeto, geralmente depois de 
um ou dois anos. A quinta e última dimensão só pode ser avaliada mais adiante, provavelmente depois de três ou cinco anos, quando os benefícios de longo prazo começam a produzir lucro (Shenhar \& Dvir, 2007).

\section{Figura 1}

Fator Temporal nas Dimensões de Sucesso

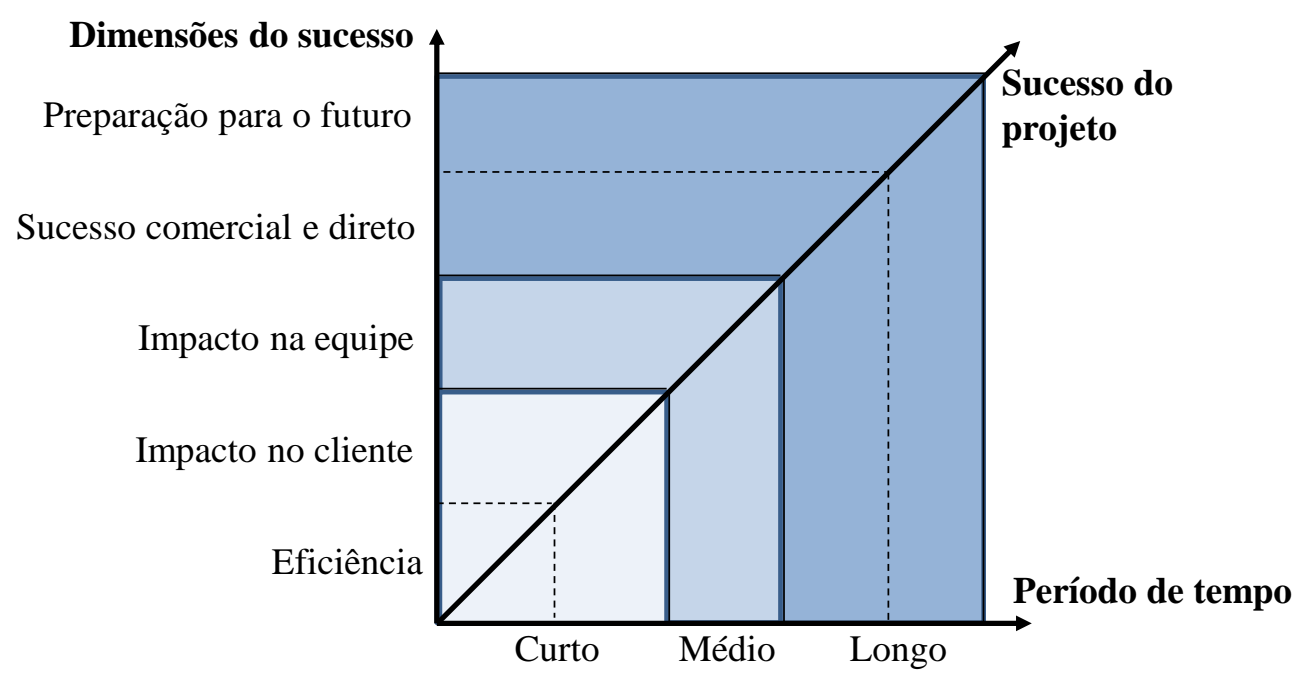

Fonte: Adaptado de Shenhar e Dvir (2007).

A metodologia de gerenciamento de projeto é outro aspecto relevante a se considerar em projetos de desenvolvimento de software. Segundo Souza e Baptistella (2017) o uso de métodos ágeis no desenvolvimento de software tem-se tornado algo cada vez mais frequente. Entre as razões para essa adoção, o Project Management Institute (PMI, 2017a) destaca a adequação do uso de métodos ágeis em projetos com maior frequência de entregas e sujeitos a incerteza, como ilustra a Figura 2.

Outra característica que influencia o sucesso de projetos, além da questão temporal e do método de gerenciamento de projeto, é o tipo de comunicação usada no gerenciamento de projetos, apresentada a seguir. 


\section{Figura 2}

Continuum do Ciclo de Vida de Projetos

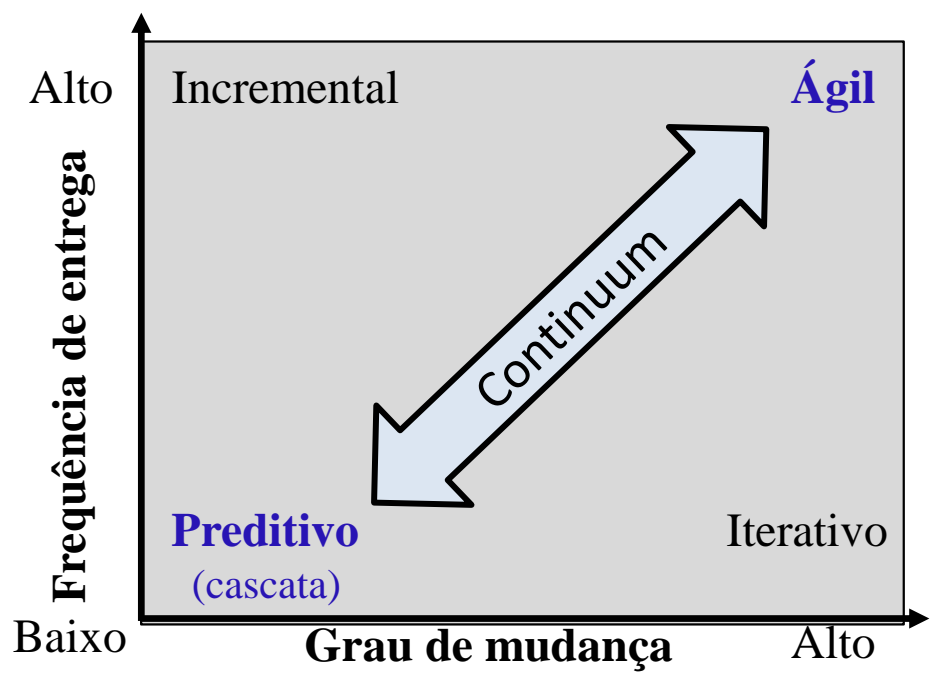

Fonte: Adaptado de PMI (2017a).

\subsection{Características da comunicação em projetos}

A comunicação pode ser definida como um processo que envolve a transmissão e a recepção de mensagens entre uma fonte emissora e um destinatário receptor, no qual as informações são codificadas na fonte e decodificadas no destino, por meio de sistemas convencionados (Chaves et al., 2008). Diversas obras na literatura caracterizaram a comunicação em projetos, em função de diversos fatores e características. No entanto, uma revisão sistemática da literatura (Rezende, Grotta, \& Prado, 2020) identificou as quatro características da comunicação mais citadas na literatura: formalidade (formal e informal), meios da comunicação, verbalização (verbal e não verbal) e internalização (interna e externa). A Tabela 1 apresenta a frequência de citação dessas características, que estão descritas a seguir. 


\section{Tabela 1}

Características da Comunicação Que Pertencem ao Quartil Superior

\begin{tabular}{|l|c|}
\hline Característica & $\begin{array}{c}\text { Frequência de citações em relação } \\
\text { ao total (\%) }\end{array}$ \\
\hline Formalidade & 23 \\
\hline Meios de comunicação & 22 \\
\hline Verbalização & 13 \\
\hline Internalização & 10 \\
\hline Outras treze & 32 \\
\hline
\end{tabular}

Fonte: Adaptada de Rezende et al. (2020).

(1) Formalidade. Djajalaksana, Zekavat e Moon (2017) classificaram dois tipos de comunicação. A primeira é a formal, que representa o conjunto de canais e meios de comunicação estabelecidos de forma consciente e deliberada. Ela se refere aos canais estruturados e oficialmente aplicados pela gerência. A segunda é a informal, que decorre de ambientes de relacionamento e é constituída por conexões pessoais não estruturadas com parceiros selecionados. Ela é utilizada pelos membros da organização para suprir deficiências e minimizar a insegurança do sistema formal de comunicação, aprofundar as agregações do grupo formal e favorecer o conhecimento coletivo.

(2) Meios de comunicação. O processo de comunicação ocorre por meio de canais ou mídias. Esses canais são representados pelas técnicas de comunicação usadas para troca de informações entre os envolvidos no projeto. Várias técnicas podem ser encontradas nos trabalhos de Chen et al. (2013), Avritzer et al. (2014), Kennedy, McComb e Vozdolska (2011), Korkala e Maurer (2014) e Tuomas et al. (2012)

(3) Verbalização. Dinsmore e Cavalieri (2003) classificaram a comunicação em termos de verbalização. A primeira categoria é a fisiológica ou paralinguística, que representa 
o resultado do relacionamento entre as diferentes partes do nosso corpo e sua manifestação externa, incluindo a própria voz. Exemplos: palidez, sudorese, temperatura corporal, tonalidade da voz e qualidade dos sons. A segunda categoria é a não-verbal. Ela refere-se à transmissão de mensagens sem o uso de palavras, sinais vocais ou paralinguísticos, sendo de extrema utilidade na transmissão de signos. Exemplos: emoções e sentimentos, como dor, cansaço, motivação etc. Por último, tem-se a categoria verbal, que é utilizada por meio de palavras. Ela se subdivide em dois tipos, a oral - por meio de palavras faladas, geralmente de forma rápida e clara, permite manter a mensagem simples e sucinta; possibilita a obtenção de feedback do receptor no momento da transmissão da mensagem - e a escrita - com maior nível de detalhamento, utilizada para explicar temas de maior complexidade ou com necessidade de formalização; possibilita melhor entendimento contínuo do receptor, deixando a mensagem à sua disposição para revisão e absorção.

(4) Internalização da comunicação. Para Djajalaksana, Zekavat e Moon (2017), a comunicação interna ocorre entre membros do projeto ou companhia; a comunicação externa é aquela direcionada para o cliente, investidores, mídia ou público em geral.

A tabela 1 mostra que há outras características da comunicação citadas na literatura, porém com menor frequência. De forma semelhante o PMI (2017b) apresenta diferentes abordagens em função das necessidades de comunicação. Para atender aos objetivos desta pesquisa, a característica de formalidade, a mais citada na literatura, está descrita na próxima seção.

\subsection{Formalidade na comunicação}

$$
\text { Zulch (2014) comparou a }
$$
comunicação formal com a informal. Para ele a CI utiliza canais como fofocas, rumores, agrupamentos sociais informais e 
comunicação fática. Por outro lado, a comunicação formal flui em três direções:

Descendente. Começa no topo e desce pelos níveis do projeto até os trabalhadores. Seu principal objetivo é fornecer informações sobre objetivos, estratégias e políticas aos subordinados. É provável que a comunicação descendente seja filtrada, modificada ou interrompida em cada nível, à medida que os gerentes decidem o que deve ser repassado aos funcionários.

Ascendente. Envolve 0 fornecimento de informações aos níveis superiores sobre o que está acontecendo nos níveis mais baixos.

Externa. Ocorre entre a equipe do projeto e pessoas que não fazem parte do projeto.

Cataldo e Ehrlich (2012) destacam a importância da CI para as equipes de software. A direção da comunicação está relacionada a carga de trabalho para gerenciar a comunicação: em uma estrutura hierárquica, há menos comunicação geral porque a comunicação flui em uma direção específica, o que minimiza a comunicação entre pessoas no mesmo nível da hierarquia. Essa importância da CI também foi percebida por Aranda et al. (2010), que concluíram por meio de estudos observacionais, que a CI apoia diferentes tipos de funções, tais como a execução e coordenação de atividades relacionadas ao trabalho, juntamente com funções sociais que também estão relacionadas à construção da confiança.

\section{Modelo de referência da pesquisa}

Nesta seção são apresentadas as proposições de pesquisa relacionadas à CI e ao sucesso em projetos. Em seguida são descritas as variáveis que compõem as proposições. O modelo de referência desta pesquisa é baseado na literatura pesquisada e foi concebido para guiar a análise da influência da CI no sucesso de projetos de desenvolvimento de software.

\subsection{Proposições da pesquisa}

Para responder à questão principal desta pesquisa foram elaboradas três proposições de pesquisa. Essas proposições (P1 a P3) foram elaboradas com base na fundamentação teórica da pesquisa e relacionam a $\mathrm{CI}$ com as dimensões de sucesso (SP1 a SP3) em projetos no curto e médio prazo. Elas foram estabelecidas a partir dos trabalhos de Aranda et al. (2010), Cataldo e Ehrlich (2012), Zulch (2014) e Djajalaksana, Zekavat e Moon (2017), que destacaram a importância do uso da CI em equipes de projetos. 
P1: O uso da CI em projetos de desenvolvimento de software tem uma associação positiva com o sucesso dos projetos em termos de eficiência do projeto (SP1).

P2: O uso da CI em projetos de desenvolvimento de software tem uma associação positiva com o sucesso dos projetos em termos de impacto para o cliente (SP2).
P3: O uso da CI em projetos de desenvolvimento de software tem uma associação positiva com o sucesso dos projetos em termos de impacto para a equipe (SP3).

O modelo desta pesquisa está ilustrado na Figura 3, que relaciona as proposições com as variáveis da pesquisa.

\section{Figura 3}

Modelo de Referência da Pesquisa

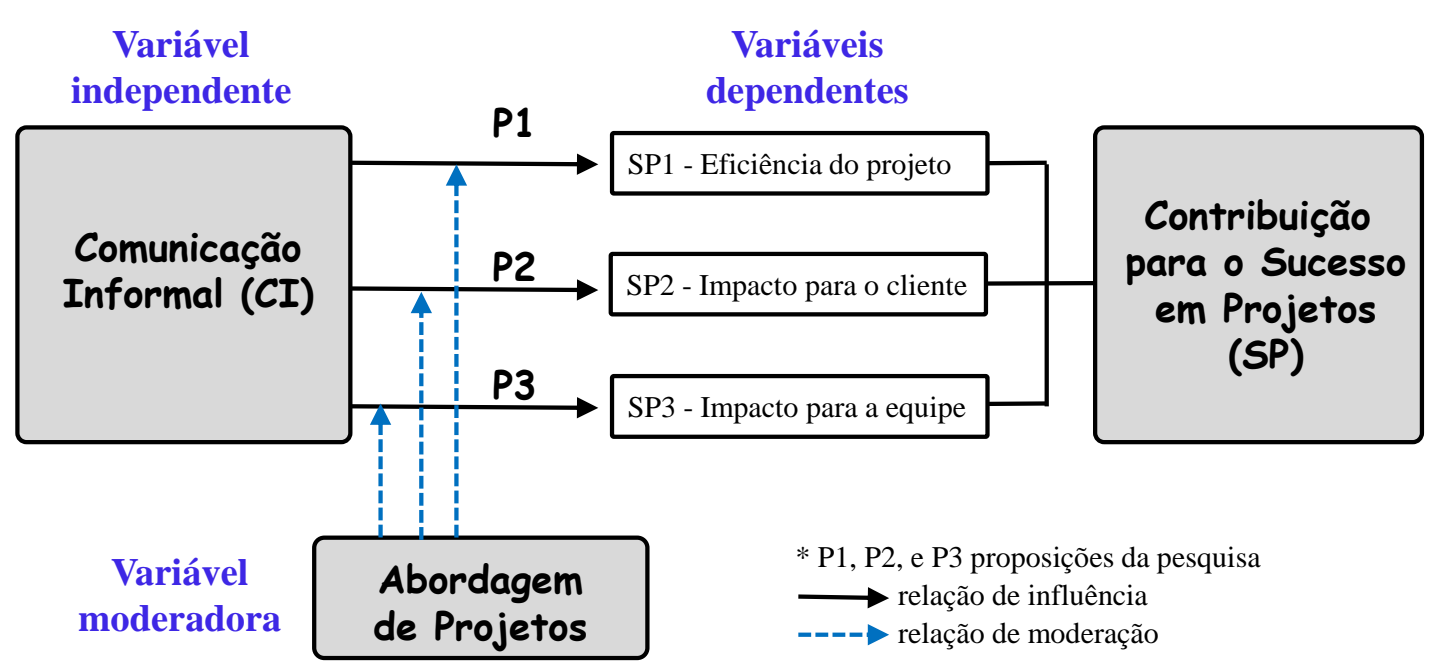

Fonte: Elaborada pelo autor.

\subsection{Variáveis da pesquisa}

O modelo desta pesquisa possui suas variáveis classificadas em: variáveis independentes (uma variável), dependentes (três) e moderadoras (uma), conforme apresentado na figura 3 . Trata-se de variáveis qualitativas, pois não possuem valores quantitativos, mas são definidas por várias categorias, podendo ser nominal ou ordinal.

Variável independente. $\mathrm{O}$ modelo de pesquisa apresenta uma única variável independente, que é a CI. Esta variável 
mede o grau de informalidade da comunicação existente no projeto com base na definição de Djajalaksana, Zekavat e Moon (2017). Trata-se de uma variável ordinal com cinco níveis: muito baixo, baixo, médio, alto e muito alto.

Variáveis dependentes. O modelo apresenta três variáveis dependentes relacionadas ao sucesso em projetos baseada nas dimensões de sucesso de Shenhar e Dvir (2007). O trabalho destes autores apresenta cinco dimensões de sucesso, porém apenas as três primeiras referem-se a resultados no curto e médio prazo, conforme o objetivo desta pesquisa. Essas três dimensões foram operacionalizadas em três variáveis do tipo ordinal com cinco níveis: péssimo, ruim, regular, bom e ótimo:

- Eficiência do projeto (SP1). Refere-se à contribuição para o cumprimento das metas de tempo, custo e escopo. Trata-se de uma variável ordinal com dois níveis: negativa ou positiva.

- Impacto para o cliente (SP2). Refere-se à contribuição para o cumprimento de requisitos, alcançar satisfação do cliente e benefícios e lealdade. Trata-se de uma variável ordinal com dois níveis: negativa ou positiva.
- Impacto para a equipe (SP3). Refere-se à contribuição para a satisfação, retenção e crescimento dos membros da equipe. Trata-se de uma variável ordinal com dois níveis: negativa ou positiva.

Variável moderadora. O modelo possui uma única variável moderadora (Vieira, 2008). Essa variável foi utilizada para moderar a análise do tipo de abordagem de gerenciamento de projeto, que foi destacado na literatura (PMI, 2017a). Esta variável identifica o tipo de abordagem utilizada no projeto. Trata-se de uma variável nominal com três categorias: ágil, cascata ou ambos.

\section{Método de pesquisa}

Esta pesquisa é fundamentada em uma revisão bibliográfica e em entrevistas com profissionais de gerenciamento de projetos, e, portanto, possui características qualitativas. A seguir são apresentados o tipo de pesquisa, as fases da pesquisa, bem como os procedimentos de coleta e tratamento dos dados.

\subsection{Características da pesquisa}

Com base na classificação de pesquisas científicas definidas por Gerhardt 
e Silveira (2009), esta pesquisa apresenta as seguintes características:

Natureza. Possui natureza aplicada, pois objetiva gerar conhecimento para aplicação prática e dirigido à solução de problemas específicos.

Tipo. É do tipo descritivo, pois descreve fatos e fenômenos de determinada realidade de maneira exata.

Estratégia. Trata-se de uma pesquisa ex-post-facto, pois tem como objetivo investigar as relações entre a CI em projetos de desenvolvimento de software e o sucesso obtido pelos projetos no curto e médio prazo.
Abordagem. A pesquisa possui abordagem qualitativa (Creswell \& Clark, 2013).

\subsection{Fases da pesquisa}

Esta pesquisa foi desenvolvida em quatro fases como ilustra a Figura 4. A primeira fase compreendeu o levantamento bibliográfico que permitiu identificar as características da comunicação formal e informal, bem como as dimensões de sucesso em projetos, apresentadas na Seção

2.

\section{Figura 4}

Fases da Pesquisa
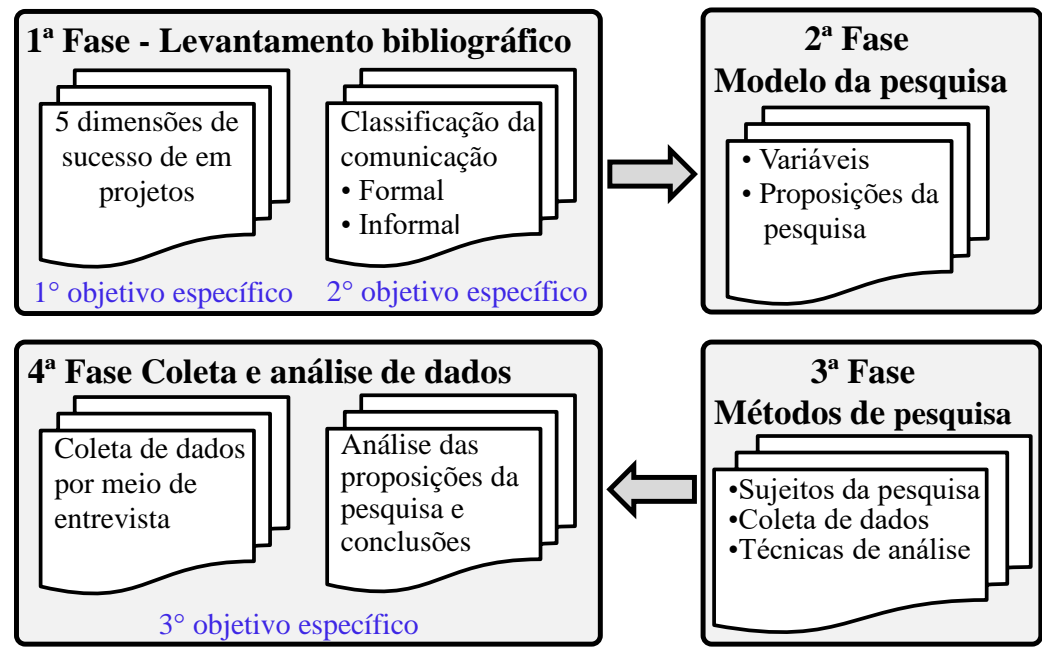

\section{$3^{\text {a }}$ Fase} Métodos de pesquisa

- Sujeitos da pesquisa - Coleta de dados

-Técnicas de análise

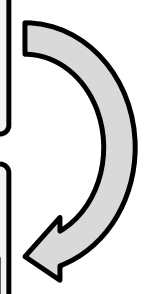

Fonte: Elaborada pelo autor.

$\mathrm{Na}$ segunda fase foi definido o modelo de referência da pesquisa, a partir do levantamento bibliográfico, e que está apresentado na Seção 3. O modelo contém as proposições da pesquisa, bem como as variáveis da pesquisa. 
A terceira fase da pesquisa descreve os métodos e procedimentos adotados, e que estão apresentados nesta seção. Nesta fase foram descritos os instrumentos e os procedimentos de coleta e tratamento de dados, e os sujeitos da pesquisa.

Por último, a quarta fase compreende a pesquisa de campo, que coletou dados por meio de entrevistas. A partir delas foram elaboradas a análise dos resultados e as conclusões. Por último cabe destacar que os dados coletados na literatura e a elaboração do modelo de referência da pesquisa foram encerrados no primeiro semestre de 2019.

\subsection{Procedimentos metodológicos}

O estudo de caso possui um protocolo baseado em cinco componentes (Yin, 2015). O primeiro é a questão de estudo apresentada na introdução. O segundo componente são as proposições de pesquisa, que foram apresentadas na seção 3.1. Os três últimos componentes - unidade de análise, instrumento e lógica para análise dos dados e critérios para interpretação e análise dos dados - estão apresentados a seguir.

\subsubsection{Empresa pesquisada e unidade de análise}

A empresa participante desta pesquisa é uma das maiores e mais importantes instituições financeiras do Brasil, com grande destaque no cenário econômico global e com forte presença nos segmentos de varejo e atacado. Possui uma área de tecnologia bem definida, com altos investimentos na continuidade e evolução dos serviços. Possui projetos de tecnologia em todas as áreas da instituição, desde dimensões pequenas a grandes, além de adotar um conjunto de metodologias de gerenciamento de projetos, baseado em recomendações atualizadas e bem definidas. A empresa selecionada constitui assim, um caso propício para análise em relação ao objetivo desta pesquisa (Yin, 2015).

As unidades de análise são os projetos de desenvolvimento de software. Os dados sobre os projetos forma obtidos de profissionais que atuaram em projetos na empresa pesquisada e que obedeceram aos seguintes critérios de seleção: devem ter experiência em projetos de desenvolvimento de software dentro do setor financeiro; atuar em fases distintas dos projetos, desde as discussões para início do projeto até as fases de pós-implantação e rollout; nível mínimo de escolaridade deve 
contemplar pós-graduação, ou graduação com experiência profissional de no mínimo cinco anos. Além disso, é importante a participação de profissionais de diversos níveis hierárquicos e de atuação, tais como engenheiros de software, desenvolvedores e líderes de projeto. A amostra mínima adotada foi de doze profissionais de TI que atuavam em projetos de desenvolvimento de software no segmento bancário.

Adotaram-se os seguintes critérios para seleção dos projetos: pertencerem a áreas diversificadas da empresa para considerar contexto distintos; finalizados ou em fase de pós-implantação para identificar o sucesso obtido no curto ou médio prazo; com equipes de tamanho variado, pois equipes maiores apresentam mais canais de comunicação (PMI, 2017b); e com abordagem de projeto ágil e cascata, que permita analisar a influência de abordagens de projeto distintas.

\subsubsection{Instrumento de coleta de dados e lógica de análise}

Dada a natureza aplicada e a abordagem qualitativa predominante da pesquisa, adotou-se a entrevista como instrumento de coleta de dados. As entrevistas foram realizadas com doze profissionais com participaram em projetos distintos, relacionados ao desenvolvimento de software.

Adotou-se nesta pesquisa a entrevista semiestruturada. Segundo Manzini (2012), as entrevistas semiestruturadas possibilitam a comparação das informações entre os participantes entrevistados. Nelas, o pesquisador pré-estabelece um roteiro, mas permite ou incentiva, que o entrevistado fale livremente sobre assuntos que vão surgindo como desdobramentos do tema principal (Gerhardt \& Silveira, 2009).

O roteiro da entrevista foi composto por perguntas abertas e fechadas, dividido em três etapas: introdução, na qual são obtidos os dados do entrevistado; contextualização, na qual o projeto é detalhado e compreendido; e proposições da pesquisa, na qual são relacionados o nível de sucesso do projeto com a CI. Dada a característica semiestruturada do instrumento, e em acordo com as recomendações de Manzini (2012), a primeira entrevista das doze foi utilizada como pré-teste para balizar as demais. As entrevistas foram realizadas no segundo semestre de 2019.

A lógica de análise, que une os dados às proposições de pesquisa, foram baseadas primordialmente na combinação de padrões e posteriormente na construção 
da explanação. Os padrões de respostas identificados nas entrevistas foram combinados e constituíram a base das evidências. Além disso, foram usados recursos de estatística descritiva, em especial o uso de frequências.

\subsubsection{Critérios e técnicas para análise dos $\underline{\text { dados }}$}

Foram utilizadas duas técnicas no tratamento de dados da pesquisa. Utilizouse a análise de conteúdo semântica, para categorizar e interpretar os dados coletados nas entrevistas. Segundo Bardin (2011), a análise de conteúdo semântica permite a exploração qualitativa de mensagens e informações. Para analisar as proposições da pesquisa utilizou-se uma técnica semelhante à análise de juízes (Medeiros et al., 2015), na qual há um julgamento realizado por um grupo de especialistas experientes na área. No caso desta pesquisa, o grupo de especialistas é composto pelos entrevistados, que analisaram a relação entre a CI e o sucesso no projeto.

Para Medeiros et al. (2015) e Pasquali (2010), uma concordância de pelo menos $80 \%$ dos especialistas pode servir de critério de decisão para confirmação da proposição. Além disso, é recomendado um número de especialistas entre seis e vinte. Com base nesses autores, esta pesquisa adotou como critério para confirmação de determinada proposição quando o número de projetos no qual se obteve confirmação da proposição é no mínimo duas vezes maior que os demais (projetos sem confirmação da proposição). A seleção de doze entrevistados também atendeu à recomendação desses autores sobre o número de especialistas.

\section{Apresentação e discussão dos resultados}

Esta seção apresenta o perfil dos entrevistados, a descrição dos projetos analisados nas entrevistas, o nível de sucesso obtido nos projetos e a análise das proposições da pesquisa. Os resultados foram baseados em doze entrevistas, denominadas de E01 a E12.

A primeira entrevista serviu como pré-teste, e por isso foi selecionado um entrevistado com experiência em projetos acima da média do grupo de entrevistados. A partir do pré-teste foram validados os itens do instrumento, as perguntas e o roteiro. Após concluído o pré-teste, o instrumento foi ajustado para sua versão final.

As entrevistas foram realizadas individualmente, em um local reservado, silencioso, sem interferência do meio externo e fora do horário de trabalho. Todos 
os entrevistados foram informados previamente sobre o objetivo da pesquisa e os temas abordados. As entrevistas foram gravadas com o consentimento dos participantes, para posterior transcrição integral e análise. As transcrições foram realizadas e revisadas manualmente pelo pesquisador, e o tempo médio de cada entrevista foi de 62 minutos, conforme Tabela 2.

\subsection{Perfil dos entrevistados}

Os entrevistados possuem idade média de aproximadamente 29 anos, sendo a idade mínima de 25 e a máxima de 36 anos. Sete entrevistados são do gênero masculino. Nove dos doze entrevistados possuem pós-graduação (stricto ou lato sensu), enquanto apenas três possuem graduação (bacharelado). As formações acadêmicas compreendem Sistemas de Informação (SI), Ciência da Computação (CC) ou Engenharias (ENG). Quanto ao tempo de experiência com projetos que envolvam desenvolvimento de software no setor bancário, a média encontrada foi oito anos, sendo no mínimo cinco e no máximo 18 anos.

Tabela 2

Dados dos Entrevistados

\begin{tabular}{|c|c|c|c|c|c|c|c|c|}
\hline \multirow[t]{2}{*}{ ID } & \multirow{2}{*}{$\begin{array}{l}\text { Idade } \\
\text { (anos) }\end{array}$} & \multirow[t]{2}{*}{ Gênero } & \multirow[t]{2}{*}{ Escolaridade } & \multirow{2}{*}{$\begin{array}{c}\text { Forma- } \\
\text { ção }\end{array}$} & \multirow{2}{*}{$\begin{array}{c}\text { Experiência } \\
\text { (anos) }\end{array}$} & \multirow{2}{*}{$\begin{array}{l}\text { Entrevista } \\
\text { (minutos) }\end{array}$} & \multicolumn{2}{|c|}{ Conhecimento } \\
\hline & & & & & & & Comunicação & Sucesso \\
\hline E01 & 29 & Masculino & Pós-graduação & SI & 9 & 82 & Muito & Médio \\
\hline E02 & 25 & Masculino & Pós-graduação & ENG & 5 & 60 & Pouco & Médio \\
\hline E03 & 26 & Feminino & Pós-graduação & ENG & 5 & 94 & Muito & Muito \\
\hline E04 & 28 & Masculino & Graduação & $\mathrm{CC}$ & 7 & 76 & Médio & Médio \\
\hline E05 & 28 & Feminino & Pós-graduação & $\mathrm{CC}$ & 6 & 47 & Médio & Médio \\
\hline E06 & 28 & Feminino & Graduação & ENG & 5 & 60 & Muito & Médio \\
\hline E07 & 31 & Masculino & Pós-graduação & ENG & 8 & 54 & Médio & Muito \\
\hline E08 & 29 & Masculino & Pós-graduação & SI & 9 & 38 & Médio & Pouco \\
\hline E09 & 32 & Masculino & Pós-graduação & ENG & 5 & 51 & Médio & Muito \\
\hline E10 & 36 & Feminino & Pós-graduação & ENG & 18 & 52 & Muito & Muito \\
\hline E11 & 26 & Feminino & Graduação & SI & 5 & 92 & Muito & Médio \\
\hline E12 & 32 & Masculino & Pós-graduação & $\mathrm{CC}$ & 9 & 43 & Muito & Muito \\
\hline Média & 29 & & & & 8 & 62 & & \\
\hline
\end{tabular}

Fonte: Dados da pesquisa. 
Os entrevistados foram questionados sobre o nível de conhecimento em relação aos temas abordados, com o objetivo de identificar sua familiaridade com esses temas. Inicialmente, a maioria respondeu ter pouco conhecimento sobre dimensões de sucesso e padrões de comunicação em projetos, porém foi possível perceber que todos eram familiarizados com os assuntos, apenas desconheciam a nomenclatura utilizada pelos pesquisadores. Com base nos dados apresentados, cabe destacar que os entrevistados selecionados atendem ao perfil previsto.

Após a realização do pré-teste iniciou-se a pesquisa com realização de cinco entrevistas. A partir da décima entrevista percebeu-se um início de convergência nas respostas dos entrevistados. Essa saturação foi obtida somente na décima segunda entrevista, quando o processo de entrevistas foi encerrado. Durante essas entrevistas os respondentes descreveram os projetos alvo da pesquisa, os quais estão apresentados a seguir.

\subsection{Descrição dos projetos}

Os doze projetos analisados possuem atividades de desenvolvimento de software em seu escopo, seja de forma parcial ou total. São projetos nos quais os colaboradores atuaram entre os anos de 2016 e 2019. A Tabela 3 apresenta os projetos alvo da pesquisa.

As características dos projetos correspondem aos requisitos estabelecidos. Os projetos pertencem a áreas diversificadas: três deles na área de tecnologia, três na área de riscos e os demais em seis áreas distintas. A grande maioria dos projetos (11 de 12) estavam finalizados ou em fase de pós-implantação, o que permite identificar mais claramente $o$ sucesso obtido no curto ou médio prazo. $\mathrm{O}$ tamanho das equipes é variado, apresenta uma média de 43 membros com desvio padrão de 51,2 e tendo a menor equipe com cinco integrantes e a maior com 175. Em relação à abordagem do projeto, nove dos projetos adotaram abordagem ágil e cinco cascata. 


\section{Tabela 3}

Dados dos Projetos

\begin{tabular}{|c|c|c|c|c|c|c|c|c|c|c|c|c|c|c|}
\hline \multirow[t]{2}{*}{ ID } & \multirow[t]{2}{*}{ Área do Projeto } & \multirow{2}{*}{$\begin{array}{l}\text { Nível de } \\
\text { Sucesso }\end{array}$} & \multirow{2}{*}{$\begin{array}{l}\text { Status do } \\
\text { Projeto* }\end{array}$} & \multirow[t]{2}{*}{ Equipe } & \multirow[t]{2}{*}{ Abordagem } & \multicolumn{3}{|c|}{ Funções** } & \multicolumn{6}{|c|}{ Fases que atuou**** } \\
\hline & & & & & & $\mathbf{L}$ & $\mathbf{E}$ & D & 1 & 2 & 3 & 4 & 5 & 6 \\
\hline E01 & Pagamentos & Bom & $\mathrm{F}$ & 175 & Ágil & - & - & & - & • & & • & - & - \\
\hline E02 & Riscos & Bom & $\mathrm{F}$ & 55 & Cascata & & - & • & & • & • & - & - & - \\
\hline E03 & Tecnologia & Bom & $\mathrm{E}$ & 15 & Ágil & • & & & & • & - & • & & \\
\hline E04 & Tecnologia & Regular & $\mathrm{P}$ & 10 & Ágil e Cascata & & & • & & • & - & • & - & $\bullet$ \\
\hline E05 & Riscos & Péssimo & $\mathrm{F}$ & 5 & Ágil & & & - & & • & - & - & - & - \\
\hline E06 & Tecnologia & Regular & $\mathrm{P}$ & 100 & Ágil & • & & & & & - & - & - & • \\
\hline E07 & Unidade Externa & Bom & $\mathrm{F}$ & 10 & Cascata & & - & - & - & - & - & - & - & - \\
\hline E08 & Atendimento & Ótimo & $\mathrm{F}$ & 70 & Cascata & & - & & & • & - & - & - & - \\
\hline E09 & Riscos & Bom & $\mathrm{F}$ & 11 & Ágil & • & & & • & • & - & - & - & • \\
\hline E10 & Rec. Humanos & Bom & $\mathrm{F}$ & 40 & Ágil e Cascata & & - & & • & $\bullet$ & $\bullet$ & & & \\
\hline E11 & Tesouraria & Bom & $\mathrm{F}$ & 10 & Ágil & - & - & & - & • & - & - & - & $\bullet$ \\
\hline E12 & Tesouraria & Regular & $\mathrm{F}$ & 15 & Ágil & • & & & & • & • & • & • & - \\
\hline
\end{tabular}

Nota * E. Em execução. F. Finalizado; P Pós-implantação.

** L. líder; E. engenheiro de sistemas; D. desenvolvedor.

*** 1 ideação; 2 definição requisitos; 3 desenvolvimento; 4 teste; 5 Implantação; 6 pós-implantação.

Fonte: Dados da pesquisa.

\section{Para completar as características} diversas dos projetos, os entrevistados participaram em diversas funções dentro do projeto - líder, engenheiro de sistemas e desenvolvedor - e em pelo menos três fases distintas do projeto. Segundo os entrevistados, todos os projetos atingiram um bom nível de sucesso, com exceção do projeto E05, que por esta razão foi descartado.

\subsection{Comunicação informal e sucesso em projetos}

A Tabela 4 apresenta como os entrevistados usaram a CI. Em seguida foram analisadas as proposições da pesquisa. A análise dos resultados obtidos em relação às proposições da pesquisa foi realizada por meio de três etapas: 


\section{Tabela 4}

Forma de uso de Comunicação Informal

\begin{tabular}{|c|c|c|c|c|}
\hline \multirow[t]{2}{*}{ ID } & \multirow{2}{*}{$\begin{array}{c}\text { Grau de uso } \\
\text { de CI }\end{array}$} & \multicolumn{3}{|c|}{ Exemplos do uso de CI } \\
\hline & & $\begin{array}{l}\text { Dia-a-dia do projeto (equipe } \\
\text { interna) }\end{array}$ & Contato com cliente & Cerimônias do modelo ágil \\
\hline E01 & Médio & $\begin{array}{l}\text { Conversas presenciais e } \\
\text { mensagens de texto }\end{array}$ & & \\
\hline E02 & Alto & $\begin{array}{l}\text { Conversas diárias entre a } \\
\text { equipe }\end{array}$ & $\begin{array}{l}\text { Ligações para o cliente } \\
\text { para tirar dúvidas }\end{array}$ & \\
\hline E03 & Médio & Discussões presenciais & & Cerimônias usam CI \\
\hline E04 & Médio & $\begin{array}{l}\text { Conversas com pessoas que } \\
\text { ajudaram o projeto }\end{array}$ & & \\
\hline E06 & Médio & $\begin{array}{l}\text { Prejudicou o projeto, pois } \\
\text { técnicas formais eram usadas } \\
\text { informalmente }\end{array}$ & & \\
\hline E07 & Muito alto & $\begin{array}{l}\text { Conversa com a equipe para a } \\
\text { percepção do andamento das } \\
\text { atividades }\end{array}$ & $\begin{array}{l}\text { Conversas frequentes } \\
\text { com clientes }\end{array}$ & \\
\hline E08 & Alto & $\begin{array}{l}\text { Proximidade física da equipe } \\
\text { foi fundamental }\end{array}$ & & $\begin{array}{l}\text { Daily meeting (reunião diária } \\
\text { da abordagem ágil) }\end{array}$ \\
\hline E09 & Médio & $\begin{array}{l}\text { Usada com a equipe no dia a } \\
\text { dia do projeto }\end{array}$ & & \\
\hline E10 & Médio & $\begin{array}{l}\text { Usada com a equipe no dia a } \\
\text { dia do projeto }\end{array}$ & & \\
\hline E11 & Muito alto & $\begin{array}{l}\text { Conversas presenciais com } \\
\text { equipe para report e } \\
\text { andamento das atividades }\end{array}$ & $\begin{array}{l}\text { Definições de } \\
\text { requisitos internas }\end{array}$ & Cerimônias usam CI \\
\hline E12 & Médio & Conversas entre a equipe & & \\
\hline
\end{tabular}

Fonte: Dados da pesquisa.

1) Obtenção dos resultados.

Informações sobre o uso de CI nos projetos dos entrevistados.

\section{2) Relação entre CI e dimensões} de sucesso. Em cada entrevista foi feita uma análise para identificar se a CI influenciou no sucesso do projeto e quais dimensões de sucesso foram influenciadas. Para evidenciar essa influência, foram solicitados exemplos aos entrevistados.
3) Síntese dos resultados. Foi elaborada uma síntese da influência da CI nas dimensões de sucesso (SP1 a SP3). A partir dessa síntese, e utilizando os critérios de aceitação, confirmouse ou não as proposições da pesquisa.

\section{$\underline{\text { 5.3.1 Comunicação informal e eficiência }}$ do projeto (P1)}

Esta proposição indaga se há uma associação positiva entre a CI e a eficiência 
do projeto (SP1). Oito dos onze entrevistados validados (E02, E03, E04, E07, E08, E09, E11 e E12) reconheceram uma influência positiva entre CI e SP1, o que atende ao critério de aceitação. Ou seja, a quantidade de entrevistados que responderam afirmativamente é duas vezes maior que a quantidade dos demais. Assim, foi confirmada a proposição P1. Em seguida há uma breve descrição dos entrevistados que responderam de forma afirmativa à proposição P1.

E02. A CI se mostrou importante pela tempestividade da comunicação. Ou seja, muito mais rápida, impactando de forma positiva o prazo do projeto.

E03. Na visão do entrevistado, a CI contribuiu positivamente para o sucesso do projeto. Segundo ele, "o telefone e as mensagens instantâneas facilitam muito conversas informais e isso contribuiu para a eficiência em termos de tempo".

E04. A CI teve influência positiva em termos de eficiência do projeto. "Quanto mais interna à equipe era a comunicação, maior a tendência de ela ser informal; opostamente, quando era direcionada ao cliente, tendia a ser formal".

E07. A CI possibilitou conhecer e entender fatos sobre o próprio projeto que não se encontravam nos documentos. Ela ajudou a conhecer a realidade do projeto.
E08. A CI foi destacada como sendo de extrema importância para o projeto, inclusive com maior importância que a comunicação formal, e contribuiu para a eficiência na comunicação.

E09. O entrevistado considerou que a CI foi positiva para a eficiência do projeto da mesma forma que o entrevistado E04.

E11. A CI foi fundamental no projeto em todas as fases possíveis, desde a definição dos requisitos formais (definições da própria equipe) quanto na comunicação e divulgação das entregas do projeto (eficiência geral).

E12. A CI foi um tipo de comunicação positiva para a eficiência, pois sem ela as trocas de conhecimento seriam mais demoradas e custosas.

\subsection{2 comunicação informal e impacto para o cliente (P2)}

Esta proposição indaga se há uma associação positiva entre a CI e o impacto para o cliente (SP2). Apenas três dos onze entrevistados validados (E01, E02 e E07) reconheceram uma influência positiva entre CI e SP2, o que não atende ao critério de confirmação. Ou seja, a quantidade de entrevistados que responderam afirmativamente não é duas vezes maior do que a quantidade dos demais. Assim, a proposição P2 não foi confirmada. 


\subsubsection{Comunicação informal e impacto para a equipe (P3)}

Esta proposição indaga se há uma associação positiva entre a CI e o impacto para a equipe (SP3). Sete dos onze entrevistados validados (E01, E02, E04, E07, E08, E09 e E10) reconheceram uma influência positiva entre CI e SP3, o que atende ao critério de aceitação. Ou seja, a quantidade de entrevistados que responderam afirmativamente é duas vezes maior que a quantidade dos demais. Assim, a proposição P3 foi confirmada. Em seguida há uma breve descrição dos entrevistados que responderam de forma afirmativa à proposição P3.

E01. A CI permitiu maior agilidade nas interações entre os membros da equipe. Porém, "é preciso saber identificar o tipo de conversa e a forma de falar que podem ser conduzidas com os membros da equipe, que apresenta diferentes perfis e personalidade".

E02. A CI afetou positivamente a velocidade de interação da equipe. Segundo o entrevistado, "a CI permite perguntas e respostas de forma rápida para sanar dúvidas por meio de comunicadores instantâneos ou telefonemas, por exemplo".

E04. A CI teve influência positiva no sucesso do projeto e impactou a equipe do projeto. Para o entrevistado, "em salas de até quatro pessoas, ocorriam conversas informais e proveitosas que influenciavam positivamente o projeto".

E07. A CI possibilitou conhecer e descobrir fatos sobre a equipe. Exemplos: você está entendendo? Está tudo indo bem? Em que eu posso te ajudar? Esse tipo de interação teve impacto positivo na equipe.

E08. A CI foi fundamental para o andamento das atividades da equipe no projeto. Ele destacou a proximidade física entre a equipe: "a quantidade de casos de teste que conseguíamos executar quando estávamos à distância era muito menor do que quando a gente se reunia presencialmente".

E09. O entrevistado considera que a CI foi positiva para a equipe do projeto e está relacionada ao tipo de stakeholder: "com a equipe do projeto ela flui melhor, mas para reportar tanto para cliente tem que ser mais formal para não perder o controle da situação".

E10. Para este entrevistado, a linguagem informal estava ligada à intimidade e ao conhecimento entre as pessoas da equipe e demais áreas. Assim, a CI impactou a equipe do projeto de forma positiva.

A Tabela 5 resume o resultado das entrevistas. 


\section{Tabela 5}

Influência da Comunicação Informal no Sucesso de Projetos

\begin{tabular}{|c|c|c|c|c|}
\hline Entrevistado & Grau de uso & \multicolumn{2}{|c|}{ Influência da CI no sucesso do projeto } \\
\hline & de CI & SP1 & SP2 & SP3 \\
\hline E01 & Médio & & Positiva & Positiva \\
\hline E02 & Alto & Positiva & Positiva & Positiva \\
\hline E03 & Médio & Positiva & & \\
\hline E04 & Médio & Positiva & & Positiva \\
\hline E06 & Médio & & & \\
\hline E07 & Muito alto & Positiva & Positiva & Positiva \\
\hline E08 & Alto & Positiva & & Positiva \\
\hline E09 & Médio & Positiva & & Positiva \\
\hline E10 & Médio & & & Positiva \\
\hline E11 & Muito alto & Positiva & & Positiva \\
\hline E12 & Médio & Positiva & & Positiva \\
\hline$\%$ de respostas positivas & & 72,7 & 27,3 & 81,8 \\
\hline
\end{tabular}

Fonte: Dados da pesquisa.

De acordo com o destaque dado pela literatura no uso da CI (Mark \& Wulf, 1999; Aranda et al., 2010; Cataldo \& Ehrlich, 2012; Zulch, 2014; Djajalaksana, Zekavat, \& Moon, 2017), a influência da CI no sucesso de curto e médio prazo de projetos se mostrou positiva nas dimensões de sucesso relacionadas à eficiência e à equipe do projeto.
5.4 As proposições de pesquisa e a abordagem dos projetos

Com base nas entrevistas foi possível categorizar os projetos quanto à abordagem adotada: ágil ou cascata (waterfall). A Tabela 6 apresenta os projetos classificados pela abordagem e associados às dimensões de sucesso em projetos. A abordagem dos projetos foi utilizada como variável moderadora.

\subsubsection{Proposições da pesquisa em relação a projetos com abordagem ágil}

A CI influenciou positivamente a maioria dos projetos com abordagem ágil. 


\section{Tabela 6}

Abordagens de Projeto e a Influência da CI no Sucesso do Projeto

\begin{tabular}{|l|c|c|c|c|}
\hline \multirow{3}{*}{ Abordagem } & \multirow{2}{*}{ Entrevistado } & \multicolumn{3}{|c|}{ Influência da CI no sucesso do } \\
projeto
\end{tabular}

Fonte: Dados da pesquisa.

As proposições de pesquisa P1 e P3 foram confirmadas, ou seja, a influência da CI na eficiência do projeto e na equipe recebeu duas vezes mais confirmações dos que respostas contrárias. A proposição P2 não foi confirmada, pois somente um projeto (E01) confirmou esta proposição, sendo que nos demais cinco projetos com abordagem ágil não houve confirmação.

\subsubsection{Proposições da pesquisa em relação a projetos com abordagem cascata}

Segundo os entrevistados, a CI influenciou positivamente todos os projetos com abordagem cascata. Como consequência, todas as três proposições da pesquisa foram confirmadas. Ou seja, houve influência da CI na eficiência, na satisfação do cliente e na equipe do projeto.

Numa primeira avaliação, os resultados contradizem o senso comum, pois no modelo cascata há menos comunicação com o cliente, e esta ocorre ao final de cada etapa. Por outro lado, na abordagem ágil, devido à ênfase na comunicação, é possível modificar as funcionalidades entre as etapas. Entretanto, é preciso considerar que a empresa analisada tem um longo histórico de uso da abordagem cascata nos projetos e só recentemente iniciou o uso da abordagem ágil. É plausível considerar que a pouca 
experiência dos seus colaboradores com a abordagem ágil tenha desfavorecido esta abordagem em relação a abordagem cascata. Esta última é amplamente conhecida na empresa pelos seus colaboradores.

\subsubsection{Análise das abordagens dos projetos}

Proposições P1 e P3 foram confirmadas no conjunto de todos os projetos, somente com aqueles que tiveram abordagem ágil, e com aqueles que tiveram abordagem cascata. Assim, a CI contribuiu para o sucesso dos projetos em termos de eficiência (P1) e impacto para a equipe (P3) independente da abordagem de gerenciamento de projetos adotada. Este resultado corrobora a importância que a comunicação tem no gerenciamento de projetos, e vai ao encontro das alegações de Zopf (2009), que destaca a comunicação como o principal recurso, mais valioso até que as questões técnicas, e capaz de influenciar diretamente o projeto.

A proposição P2 não foi verificada em projetos com abordagem ágil. Por outro lado, a melhoria da comunicação é um fator para a adoção da abordagem ágil (PMI, 2017b). Além disso, segundo Yagüe et al. (2016) a comunicação é mais crítica no caso de desenvolvimento de software em escala global. Como consequência, pode-se inferir que a não confirmação da proposição $\mathrm{P} 2$ mostra que a CI trouxe benefícios perceptíveis aos membros da equipe (P3), mas não para os clientes (P2). Essa inferência é corroborada pela adoção do Design Thinking com resultados satisfatórios em projetos de desenvolvimento de software (Valentim, Silva, \& Conte, 2017; Driscoll, 2016). Isto porque, o Design Thinking privilegia o envolvimento do cliente e, consequentemente, cria um canal de comunicação mais eficaz com ele.

\subsection{Limitações da pesquisa}

Esta seção apresentada as limitações da pesquisa, que influenciam a abrangência e a validade dos resultados. As limitações que mais se destacaram nesta pesquisa se referem à técnica de análise dos dados e à generalização dos resultados.

Técnica de análise dos dados. Os dados das entrevistas foram analisados com uso da técnica de análise de conteúdo semântica. A interpretação desse conteúdo foi feita pelo autor, o que atribui subjetividade aos resultados.

Generalização dos resultados. Todos os entrevistados pertencem a uma única empresa, o que não permitem generalizações para outras empresas e nem mesmo para a própria empresa pesquisada. 
Isto porque, foi feita uma análise qualitativa em doze projetos de desenvolvimento de software e estes não constituem uma amostra significativa em relação a grande quantidade de projetos da empresa. Porém, o tipo de pesquisa realizada objetivou aprofundar o conhecimento do tema por meio de mais de doze horas de entrevistas transcritas.

\section{Conclusões}

O objetivo deste trabalho foi analisar a influência da CI no sucesso de curto e médio prazo de projetos de desenvolvimento de software em uma instituição bancária brasileira. Para atingir este objetivo, efetuou-se uma pesquisa qualitativa e descritiva com uso da técnica de análise de conteúdo, que contou com o apoio de doze profissionais experientes no gerenciamento de projetos em uma instituição bancária brasileira. A resposta à questão de pesquisa e as conclusões deste trabalho estão agrupadas a seguir em função dos objetivos específicos:

\section{Identificar as principais dimensões} de sucesso em projetos: foram identificadas, a partir do trabalho de Shenhar e Dvir (2007), cinco dimensões de sucesso em projetos. Trata-se de uma abordagem amplamente referenciada pela literatura.
Identificar as características da comunicação relacionadas à formalidade: foram identificadas sete características da comunicação na literatura, e entre elas a característica relacionada à formalidade na comunicação, alvo deste trabalho. Esta característica foi descrita em detalhes.

Analisar a relação entre as características informais da comunicação em projetos de desenvolvimento de software e o sucesso obtido pelos projetos no curto e médio prazo: esta análise foi feita por meio de três questões norteadoras da pesquisa, cujos resultados e contribuições estão apresentadas a seguir.

Duas das três questões norteadoras tiveram resposta afirmativa. Desse modo, foi verificada uma associação positiva entre o uso de CI e o sucesso em projetos em termos de eficiência e contribuição para a equipe do projeto. Este resultado se alinha à literatura que enfatiza a importância da CI em projetos. Por outro lado, ao contrário da literatura, foram obtidos melhores resultados em projeto com abordagem cascata, ou seja, duas proposições foram verificadas em projetos com abordagem ágil e as três nos projetos com abordagem cascata. Mesmo considerando que a empresa analisada tem maior experiência na abordagem cascata, e que pode ter influenciado o resultado, isso chama a 
atenção ao fato de que a abordagem ágil, tão evidenciada pela literatura, não foi superior a abordagem cascata em termos de contribuição da CI no sucesso do projeto. Este resultado sugere futuras análises sobre a CI em abordagens híbridas - com características da abordagem ágil e cascata - destacada pela literatura em anos recentes.

A questão sobre a associação positiva da CI com a satisfação do cliente teve um resultado negativo. Apesar de ter sido citada de forma positiva em algumas entrevistas, a maioria dos entrevistados destacou a comunicação formal, e não a CI, como a mais importante no relacionamento com o cliente. Deste fato, é plausível inferir que a comunicação formal é relevante no desenvolvimento de software. Isto pode estar associado ao desafio de definir e elicitar requisitos junto aos clientes, em projetos de desenvolvimento de software, que levam as equipes de projeto a valorizar a comunicação formal como uma alternativa para evitar conflitos na especificação do software.

As contribuições desta pesquisa são relevantes para o sucesso de projetos, principalmente em grandes organizações, tais como a do setor bancário descrita nesta pesquisa. $\mathrm{Na}$ sociedade atual, a acelerada migração de processos e soluções para meios digitais é realizada por meio de projetos de tecnologia. Estes projetos utilizam abordagem de gerenciamento de projetos cascata, ágil ou híbrida. Assim, sugere-se trabalhos futuros que permitam generalizar os resultados desta pesquisa em organizações do setor bancário e outros setores.

A pesquisa também contribui para o campo de conhecimento em gerenciamento de projetos. Isto porque, a área de TI executa projetos predominantemente com o uso da abordagem ágil, cuja proposição de pesquisa não se confirmou em relação ao impacto para o cliente. Este resultado sugere a realização de pesquisas futuras sobre o uso da CI em técnicas e métodos que privilegiem o envolvimento do cliente, tais como Design Thinking e Project Model Canvas.

\section{Referências}

Al-Ahmad, W., Fagih, K., Khanfar, K., Alsamara, K., Abuleil, S., \& AbuSalem, H. (2009). A Taxonomy of an IT Project Failure: Root Causes. International Management Review, 5(1), 93-104.

Aranda, G. N., Vizcaino, A., Palacio, R. R., \& Moran, A. L. (2010). What information would you like to know about your co-worker? a case study. 5th IEEE International Conference on Global Software Engineering - ISSN 2329-6305. 135-144. 
Avritzer, A. et al. (2014). Survivability models for global software engineering. In: IEEE 9th International Conference on Global Software Engineering. Shanghai, China, 2014, pp. 100-109, ISSN 2329-6305.

Bardin, L. (2011). Análise de Conteúdo. (4. Ed.). Brasil: Edições 70.

Buchanan, J. (2008). Measuring up. PM Network. Project Management Institute, 22(9), 50-55.

Cataldo, M., \& Ehrlich, K. (2012). The impact of communication structure on new product development outcomes. Proceedings of the SIGCHI Conference on Human Factors in Computing Systems. New York, NY, USA: ACM, 30813090.

https://doi.org/10.1145/2207676.22 08722 .

Chaves, L. E., Neto, F. H. S., Pech, G., \& Carneiro, M. F. S. (2008).

Gerenciamento da comunicação em projetos. (4. ed.). Rio de Janeiro: FGV Editora.

Chen, Q.-L. et al. (2013). A model for project communication medium evaluation and selection.

Concurrent Engineering, 21(4), 237-251. https://doi.org/10.1177/1063293X1 3493096.

Creswell, J. W., \& Plano Clark, V. L. (2007). Designing and conducting mixed methods research. Thousand Oaks, CA: Sage.

Dinsmore, C., \& Cavalieri, A. (2003). Como se Tornar um Profissional em Gerenciamento de Projetos.
Project Management Professional. QualityMark.

Djajalaksana, M. L., Zekavat, P. R., \& Moon, S. (2017). Effectiveness of on-site communication in residential housing projects. ISARC. Proceedings of the International Symposium on Automation and Robotics in Construction, 34, 1-6.

Dvir, D., Raz, T., \& Shenhar, A. (2003). An Empirical Analysis of the Relationship between Project Planning and Project Success. International Journal of Project Management, 21, 89-95. https://doi.org/10.1016/S02637863(02)00012-1

Gerhardt, T. E., \& Silveira, D. T. (2009). Métodos de Pesquisa. Porto Alegre: UFRGS.

Hartman, F., \& Ashrafi, R. 2002. Project management in the information systems and information technologies industries. Project Management Journal, 33(3), 5-15.

Kennedy, D. M., Mccomb, S. A., \& Vozdolska, R. R. (2011). An investigation of project complexity's influence on team communication using Monte Carlo simulation. Journal of Engineering and Technology Management, 28(3), 109-127. https://doi.org/10.1016/j.jengtecma n.2011.03.001

Korkala, M., \& Maurer, F. (2014). Waste identification as the means for improving communication in globally distributed agile software development. Journal of Systems and Software, 95, 122-140. 
https://doi.org/10.1016/j.jss.2014.0 3.080

Rezende, L. Z., Grotta, A., \& Prado, E. P. V. (2020). Software Projects Success and Informal Communication: A Brazilian Bank Case Study In: 22nd International Conference on Enterprise Information Systems, Prague, 2020, 1, pp.169-176. https://doi.org/10.5220/0009346201 690176.

Li, Y., Liu, X., \& Ning, Y. (2021). Disentangling the failure of benefits realization in public institutional building projects: a paradoxical understanding of formalization. Journal of Asian Architecture and Building Engineering. https://doi.org/10.1080/13467581.2 020.1869015 .

Lu, X., Liu, L., \& Liu, L. (2009). Relationship research between communication activities and success indexes in small and medium software projects. 1 st International Conference on Information Science and Engineering, ICISE 2009, IEEE, 5022-5025. https://doi.org/10.1109/ICISE.2009. 879.

Machado, F. J., \& Martens, C. (2015). Project management success: A bibliometric analysis. Revista de Gestão de Projetos, 6(1), 28-44. https://doi.org/10.5585/gep.v6i1.31 0 .

Manzini, E. J. (2012). Uso da entrevista em dissertações e teses produzidas em um programa de pós-graduação em educação. Revista Percurso NEMO, 4(2), 149-171.
Medeiros et al., 2015. Modelo de validação de conteúdo de Pasquali nas pesquisas em Enfermagem. Revista de Enfermagem Referência, 4, 127135.

Morioka, S., \& Carvalho, M. M. D. (2014). Análise de fatores críticos de sucesso de projetos: um estudo de caso no setor varejista. Production, 24(1), 132-143. https://doi.org/10.1590/S010365132013005000015.

Pasquali, L. (2010). Instrumentação psicológica: fundamentos $e$ práticas. Porto Alegre, Artmed.

PMI. (2017a). Agile Practice Guide. Newton Square, Pennsylvania: Project Management Institute.

PMI. (2017b). A Guide to the Project Management Body of Knowledge PMBOK Guide, 6th ed. Newton Square, Pennsylvania: Project Management Institute.

Qi, Y., Qian, Q.K., Meijer, F.M., \& Visscher, H.J. (2021). Unravelling Causes of Quality Failures in Building Energy Renovation Projects of Northern China: Quality Management Perspective. Journal of Management in Engineering, 37(3), 04021017. https://doi.org/10.1061/(ASCE)ME. 1943-5479.0000888.

Shenhar, A. J., \& Dvir, D. (2007). Reinventing project management: The diamond approach to successful growth and innovation. Boston: Harvard Business School Press. 
Souza, F. S., \& Baptistella, M. M. P. (2017). Uso de metodologias ágeis no desenvolvimento de softwares. Revista Empreenda UniToledo, (1)1, 204-219.

Srivastava, S., Kumar, A. (2021). Agile approach as a universal remedy for the usual failure in the development of software projects. Recent Patents on Engineering, 15(2), 188-194. https://doi.org/10.2174/1872212114 666200117112617.

Tuomas, N. et al. (2012). Reflecting the choice and usage of communication tools in global software development projects with media synchronicity theory. Journal of Software: Evolution and Process, 24(6), 677-692. https://doi.org/10.1002/smr.566.

Vieira, V. A. (2008). Moderação, mediação, moderadora-mediadora e efeitos indiretos em modelagem de equações estruturais: uma aplicação no modelo de desconfirmação de expectativas. Revista de Administração, São Paulo, 44(1), 17-33.

Yagüe, A., Garbajosa, J., Díaz, J., \& González, E. (2016). An exploratory study in communication in Agile Global Software Development. Computer Standards \& Interfaces, 48, 184197. https://doi.org/10.1016/j.csi.2016.0 6.002 .

Yin, (2015). Case Study Research and Applications: Design and Methods. USA; Sage.

Zopf, S. (2009). Success factors for globally distributed projects. Software Process: Improvement and Practice. Wiley Online Library, 14(6), 355-359. https://doi.org/10.1002/spip.423.

Zulch B. (2014). Communication: The Foundation of Project Management. Procedia Technology. https://doi.org/10.1016/j.protcy.201 4.10.054. 